\title{
REPRESENTAÇÕES SOCIAIS DE ENVOLVIDOS NA IMPLEMENTAÇẨO DO PEIBF - UM EXEMPLO DO RIO GRANDE DO SUL
}

\author{
(Social representations of involved in the implementation of \\ PEIBF - an example of Rio Grande do Sul)
}

Greici Lenir Reginatto Cañete

Dorotea Frank Kersch ${ }^{2}$

(Universidade do Vale do Rio dos Sinos -UNISINOS/ RS)

\section{ABSTRACT}

This paper aims to present considerations about the implementation of the Bilingual Intercultural Border Area School Project (PEIBF) by analyzing social representations and attitudes of managers and teachers in relation to education system and PEIBF's methodology. In this sense, the display state of the art of this project in two so called mirror schools, and the result of semi-structured interviews and field notes of two visits are presented. The first results show the complexity of the implementation of this language policy proposal. There is an agreement between both sides on the need to form students with both cultures enhancing the integration of the border and the respect to the diversity that is encountered in the area.

\section{Key words:}

\section{RESUMO}

Este artigo tem por objetivo tecer considerações a respeito da implementação do Projeto Escolas Interculturais Bilingues de Fronteira (PEIBF), em duas escolas-espelho, analisando representações sociais e atitudes de gestores e professores em relação aos sistemas de ensino da escola parceira $e$ metodologia do PEIBF. Os dados foram gerados com entrevistas

1. Professora colaboradora no Instituto Cervantes de Porto Alegre, tradutora pública e mestranda em Linguística Aplicada UNISINOS.

2. Mestrado em Estudos da Linguagem (UFRGS) e Doutorado em Filologia Românica (Christian Albrechts Universität zu Kiel - Alemanha). Professora pesquisadora do Programa de Pós-Graduação em Linguística Aplicada. 
semiestruturadas e anotações em diário de campo de duas visitas feitas. Os primeiros resultados mostram a complexidade da execução dessa proposta de política linguística. Há consenso entre ambas as partes sobre a necessidade da formação intercultural os alunos, que promova a integração da fronteira e o respeito à diversidade.

Palavras-chave: projeto escolas interculturais bilingues de fronteira. atitudes. representações sociais.

\section{Introdução}

O Brasil faz fronteira com nove dos onze países da América do Sul. Somente com a fronteira com o Uruguai, são $1.068 \mathrm{~km}$, dos quais $320 \mathrm{~km}$ são de fronteira seca. Ao longo dessa fronteira seca, encontram-se três das cidades gêmeas: Chuí-Chuy, Aceguá-Aceguá, Santana do Livramento-Rivera, além de Jaguarão-Río Branco e Quaraí-Artigas, ligadas por pontes. Se, em outros momentos da história, esses espaços fronteiriços foram alvo de conflitos, a partir do estabelecimento do MERCOSUL, estreitou-se o diálogo com esse país limítrofe (assim como com os demais).

Em 2002, lançou-se a Nova Agenda de Cooperação e Desenvolvimento Fronteiriço, que prevê quatro grupos de trabalho: saúde; cooperação policial e judicial; educação e formação profissional; e meio-ambiente e saneamento. A Nova Agenda é importante instrumento para encaminhamento de solução aos problemas das comunidades que vivem na fronteira entre o Estado do Rio Grande do Sul e o Uruguai. Segundo informação da página na internet do governo no estado do Rio Grande do Sul ${ }^{3}$, tratase de uma ação de competência dos Ministérios das Relações Exteriores do Brasil e do Uruguai, a qual, além de criar condições para o desenvolvimento integrado da região de fronteira entre os dois países, a fim de obter um melhor aproveitamento dos recursos disponíveis, também busca ampliar o horizonte de cooperação

3. Disponível em http://www.sema.rs.gov.br/conteudo.asp?cod_menu=4\&cod_ conteudo $=7342$, acesso em 08.10.2011. 
bilateral, com ênfase em ciência, tecnologia e inovação, educação e grandes projetos de infraestrutura.

Na esteira da integração da fronteira, foi criado, em 2005, por uma ação bilateral Brasil-Argentina, o Projeto Escola Intercultural Bilíngue de Fronteira (PEIBF), com a finalidade de promover o intercâmbio entre professores dos países do MERCOSUL. A principal meta do Projeto é a integração de estudantes e professores brasileiros com os alunos e professores dos países vizinhos. Com a integração, esperase a ampliação das oportunidades do aprendizado da segunda língua. Como metodologia, prevê-se o trabalho por projetos de aprendizagem. A ideia é que os professores, de ambos os países, planejem as aulas conjuntamente e determinem as partes do projeto em que se dará o intercâmbio, pelo menos uma vez por semana. No PEIBF, portanto, não se trata de ensino DE língua estrangeira, mas ensino EM língua estrangeira, criando-se um ambiente real de bilinguismo para os alunos. De acordo com o Portal do MEC 4 , em 2010 havia 13 escolas do Brasil e 13 de quatro países - Argentina, Uruguai, Paraguai e Venezuela ${ }^{5}$. No Rio Grande do Sul, são oito escolas, sempre com uma espelho no país vizinho: Uruguaiana /Paso de los Libres (Argentina) (1); São Borja/ Santo Tomé(Argentina) (2); Itaqui/Alvear(Argentina) (1); Itaqui/La Cruz (Argentina) (1); Chuí/Chuy (Uruguai) (1) e Jaguarão/Río Branco (Uruguai) (2). É de um desses casos que trataremos aqui.

O objetivo deste artigo é tecer considerações a respeito da implementação do PEIBF, analisando as representações sociais e atitudes de gestores e professores envolvidos diretamente na execução do projeto, com foco em duas escolas-espelho da fronteira sul do Rio Grande do Sul. Para dar conta desse objetivo, nosso trabalho acha-se dividido em quatro partes: a apresentação do contexto da pesquisa; a fundamentação teórica, com a revisão de aspectos como representações sociais, crenças e atitudes, e política linguística; a metodologia, com a descrição da forma de obtenção dos dados; e a discussão dos resultados.

4. Disponível em: http://portal.mec.gov.br/arquivos/pdf/tabela_fronteira.pdf, 16/04/2011.

5. Esse número, entretanto, é controverso, como se verá adiante. 


\section{Fundamentação teórica}

Para dar conta do objetivo de analisar as representações sociais e atitudes de professores e gestores envolvidos diretamente na implementação do PEIBF, com foco em duas escolas espelho, faremos, na sequência, a revisão de aspectos teóricos necessários para a discussão de nossos resultados mais adiante, dividida em dois eixos: representações, atitudes linguísticas e identidade de nossos sujeitos, e política linguística, que está por trás do PEIBF.

\subsection{Representações, atitudes e identidade}

A Teoria das Representações Sociais (MOSCOVICI, 1978) parte do pressuposto de que os indivíduos, em suas interações e nas experiências vividas no seio dos grupos sociais de que fazem parte, formam representações sobre objetos, sujeitos, situações e circunstâncias de seu dia a dia. Essas representações influenciam o desenvolvimento de crenças, atitudes e condutas dos sujeitos em relação a esses objetos e situações, à medida que os representam. As representações são sociais porque as construímos e nos constituímos em relação aos outros por meio da linguagem. Moscovici (2003, p. 21) entende representação social como:

um sistema de valores, ideias e práticas, com dupla função: primeiro, estabelecer uma ordem que possibilitará às pessoas orientar-se em seu mundo material e social e controlá-lo; e, em segundo lugar, possibilitar que a comunicação seja possível entre os membros de uma comunidade, fornecendo um código para nomear e classificar, sem ambiguidade, os vários aspectos de seu mundo e da sua história individual e social.

A representação social é, portanto, uma das perspectivas por meio das quais se procura compreender como se dá a elaboração e transmissão de conceitos e o modo como os indivíduos percebem e constroem a realidade. O sujeito, na perspectiva da representação social, é compreendido como pensador ativo, não um simples processador e reprodutor de conhecimento. Ele se constitui e é 
constituído na interação com outros (e não criado do nada, no vazio) num dado contexto socio-histórico.

Um conceito periférico ao de representações é o de crenças, e muitas vezes pode ser confundido com ele. Entretanto, Barcelos (2004, p. 132), ao fazer um estudo comparativo entre os diferentes conceitos usados em relação a crenças, mostra que essas se referem à natureza da linguagem e ao ensino/aprendizagem de línguas, enquanto o termo representações (além dos outros mencionados, como filosofia de aprendizagem de línguas dos aprendizes, conhecimento metacognitivo, teorias folclórico-linguísticas de aprendizagem, cultura de aprender, entre outros) dá ênfase ao aspecto cultural e à natureza social de crenças, colocando-as como ferramentas que ajudam os alunos a interpretar suas experiências.

Para nosso estudo aqui, portanto, utilizamos o conceito de representações, porque o entendemos, da forma como mostra Barcelos (2004): mais amplo que o de crenças que nos coloca diante de aspectos relacionados à cultura e à constituição identitária. Além disso, pela linguagem, os sujeitos se manifestam em relação a si e aos outros.

As atitudes linguísticas, por sua vez, são avaliações subjetivas (e muitas vezes inconscientes) feitas em relação às variedades faladas em determinada comunidade e, na maioria das vezes, são estendidas também a seus falantes. Para Appel \& Muysken (1996, p. 29), as línguas não são somente instrumentos objetivos e socialmente neutros que transmitem um significado, mas também estão relacionadas com as identidades dos grupos sociais ou étnicos (tradução nossa) ${ }^{6}$. Para os autores, isso tem como consequência a avaliação social das línguas e o desenvolvimento de atitudes: se há uma relação intensa entre língua e identidade, esta relação deveria se manifestar nas atitudes dos indivíduos para com as línguas e seus usuários (p.30) (tradução nossa) ${ }^{7}$.

6. Están relacionadas con las identidades de los grupos sociales o étnicos.

7. Si hay una relación intensa entre lengua y identidad, esta relación debería manifestarse en las actitudes de los individuos hacia esas lenguas y sus usuarios (p. 30). 
Nos estudos de atitudes, busca-se saber que significado social tem a variedade linguística de uma pessoa para outras (Myers-Scotton, 2006), ou seja, quem usa determinada variedade, onde e para que a usa leva outros a associar esse uso a uma determinada condição social:

Se principalmente imigrantes relativamente pouco instruídos são os falantes de uma língua e ela não é utilizada em interações oficiais, como o turco em grande parte da Europa Ocidental, então alguém que fala turco é assumido como sendo um imigrante sem educação (mesmo que este falante possa ser bem educado e mantenha um trabalho profissional (Myers-Scotton, 2006, p. 110) ${ }^{8}$.

Isso quer dizer que falar em atitudes é falar em avaliação e reconhecer que elas estão condicionadas ao sistema de valores que, por sua vez, é acordado pelos indivíduos de uma sociedade, grupos sociais e/ou comunidades de fala (Schneider, 2007, p. 83). As atitudes linguísticas, entretanto, não são constantes; assim como as línguas, elas mudam, porque, como aquelas, são aprendidas, socialmente coconstruídas na interação face a face.

As atitudes estão ligadas ao conceito de identidade. As identidades (usamos a expressão no plural, porque entendemos que não temos uma identidade, mas somos o resultado de várias), na atualidade, são caracterizadas como fluidas, incoerentes, instáveis, em constante em mudança. Para Hall (2005), língua, cultura e identidade estão inter-relacionadas. Por meio da linguagem nós nos constituímos, criamos uma impressão de nós mesmos, e é na e pela linguagem que comunicamos nossa identidade aos outros, dentro e fora do(s) grupo(s) a que pertencemos. A língua que falamos, portanto, nos identifica com nossa origem, nossa história, nossa cultura, com o grupo a que pertencemos (BAKER, 1993).

Numa comunidade multilíngue, manter uma ou outra língua (ou mesmo querer aprendê-la) está relacionado à atitude que os

8. Tradução livre de: If mainly relatively uneducated immigrants are the speakers of a language and it is not used in official nteractions, such as Turkish in much of Western Europe, then someone who speaks Turkish there is assumed to be an uneducated immigrant (even though this speaker may be well educated and hold a professional job) (Myers-Scotton, 2006, p. 110). 
falantes têm em relação a ela. Atitudes linguísticas são avaliações subjetivas sobre o valor das variedades em si e sobre seus falantes. Quando as atitudes se estendem aos falantes, elas tomam, muitas vezes, a forma de atributos, carregados de preconceitos, e aí vêm os mitos, que se impõem como verdades absolutas. Língua(gem) e identidade, portanto, levam, o tempo todo, a mudanças internas e externas; a todo instante estamos negociando nossa(s) identidade(s) e, por essa razão, na atualidade, nossa(s) identidade(s), como dissemos acima, não é fixa, muito diferente da forma como era percebida antes que os debates sobre globalização estivessem tão presentes no discurso acadêmico.

O estudo das representações, atitudes e identidade nos auxiliará a elucidar e compreender o que professores e gestores participantes da pesquisa pensam a respeito da implementação do PEIBF em sua escola e a respeito dos seus parceiros do país vizinho, corresponsáveis na consecução dos objetivos do projeto, que se configura como uma política linguística para as regiões de fronteira, tópico que é apresentado na sequência.

\subsection{Política linguística}

A política linguística está relacionada às decisões a respeito do uso de uma língua, à opção por determina língua em determinado contexto. Nesse sentido, quando falamos de política linguística, estamos falando de "um conjunto de escolhas conscientes referentes às relações entre língua(s) e vida social” (Calvet, 2002: 145). Quando se trata da questão de fronteira, Mackey (2008) afirma que é necessário adotar uma política que faça com que a maior parte das pessoas se sintam em casa.

Toda política precisa ser implementada, e isso se faz com planejamento linguístico. Ainda segundo Calvet (2002), o grupo responsável pela elaboração de uma política linguística pode ser uma entidade menor, como a família, mas somente o Estado estaria habilitado para passar ao estágio do planejamento, de pôr em prática as escolhas linguísticas. De um modo geral, o conceito de política 
linguística diz respeito a um conjunto de medidas governamentais e/ ou institucionais, que visam a fomentar a vitalidade e a manutenção de uma variedade linguística e/ou a sua padronização.

O bilinguismo não está relacionado apenas a indivíduos, família ou comunidade. As línguas estão ligadas direta ou indiretamente à política da(s) nação(ões). No caso de educação bilíngue, que é o foco do PEIBF, é necessário estabelecer relações com a filosofia e a política da sociedade. O ensino bilíngue, segundo Baker (1993), não se baseia somente em preferências pedagógicas, nem reflete apenas decisões curriculares. Ele se sustenta em crenças e atitudes em relação ao outro, na igualdade de oportunidades, nos direitos individuais e coletivos, na assimilação ou integração (BAKER, 1993, p. 339). Nesse sentido, todos - alunos, gestores, professores, promotores de políticas de ensino - precisam estar cientes de que educação bilíngue se dá além da sala de aula, dada a complexidade do processo. Para verificar se isso se está dando na prática, examinemos, na sequência, o histórico do PEIBF, e como está sua implementação.

\section{O histórico e o status do PEIBF}

O Projeto Escolas Interculturais Bilíngues de Fronteira (PEIBF) nasceu de uma intervenção, uma política linguística para as áreas de fronteira do Brasil com os países vizinhos. O PEIBF pretende ser planejamento e aplicação de ações educativas para promover as línguas oficiais do Mercosul, o espanhol e o português, e a integração necessária ao bloco econômico. O planejamento linguístico, como mencionado acima, é a aplicabilidade de uma política linguística, e o planejamento linguístico agirá sobre o ambiente, para intervir no peso das línguas, na sua presença simbólica (CALVET, 2007, p. 73).

Fronteira é uma região mais que geográfica, é, sobretudo, cultural e simbólica (GARCIA, 2010). A necessidade de promover as culturas e as línguas da região da fronteira em questão veio da implantação do MERCOSUL, que deu uma nova direção às relações 
de vizinhança para os países do bloco. Desde então, a política linguística para a região também foi redirecionada à integração, começando pela oficialização do português e do espanhol como idiomas oficiais do MERCOSUL, passando pela obrigatoriedade do ensino de espanhol no Brasil, lei $N^{\circ} 11.161$, de 5 de agosto de 2005․ Na Argentina, também há a obrigatoriedade do ensino de português, aprovada pela lei $n^{0} 26.468 / 2008^{10}$. No Uruguai não há disponibilidade de documento de decreto-lei de domínio público, mas, na página da ANEP (Administración Nacional de Educación Pública), fala-se sobre as políticas linguísticas do Uruguai e a inclusão do português como língua regional no ensino público, além de outras línguas estrangeiras ${ }^{11}$. Também na página do Instituto de Profesores Artigas, que é a instituição que forma professores em diversas áreas, consta curso de formação para professor de português $^{12}$. O objetivo principal do PEIBF é buscar um modelo comum de ensino intercultural. Desse modo, as escolas envolvidas no projeto devem:

Consolidar uma identidade cultural regional e promover a integração, formar cidadãos ativos para converter a fronteira em um espaço democrático de cooperação, um cidadão sensível à interculturalidade [...] Além disso, o aluno egresso do programa terá um domínio suficiente das línguas portuguesa e espanhola para interatuar com seus pares em contextos previsíveis de intercâmbio

(MECyT \& MEC; 2008)

Segundo Thomaz (2010), o primeiro acordo relativo ao projeto foi firmado entre Brasil e Argentina em 2004, iniciando em 2005. A partir de 2009, passou a ser um projeto multilateral, estendendo-se a mais três países: Paraguai, Venezuela e Uruguai. Hoje, o número de

9. Disponível em: http://www.planalto.gov.br/ccivil_03/_Ato2004-2006/2005/ Lei/L11161.htm, acesso em 02.03.2012

10. Disponível em: http://www.bnm.me.gov.ar/giga1/normas/13516.pdf, acesso em 02.03.2012

11. Disponível em: http://www.anep.edu.uy/anepportal/servlet/main004?229, acesso em 16/04/2012

12. Disponível em: http://www.dfpd.edu.uy/ipa/index.html, acesso em 16/04/211. 
cidades participantes do PEIBF está em dezessete, em vinte e quatro escolas de fronteira (THOMAZ, 2010) ${ }^{13}$.

$\mathrm{Na}$ parceria Brasil e Uruguai, que iniciou em 2009, são participantes as cidades de Jaguarão/RS e Rio Branco(UY), e Chuí /RS com a cidade de Chuy (UY), os dois pares de cidades-gêmeas envolvidas até o momento, num total de 6 escolas. Entre esses dois países, existe um Acordo para a criação de escolas e institutos binacionais fronteiriços, desde 2005, que estende o PEIBF ao Uruguai, estabelecendo que "As escolas e/ou institutos terão como objetivo promover a qualificação e a formação profissional, permitindo a inclusão social da população fronteiriça, tendo na educação um elemento de fortalecimento do processo de integração" (Acordo para criação de Escolas e-ou Institutos Binacionais Fronteiriços, artigo III, 2005 ${ }^{14}$ ).

$\mathrm{Na}$ escola brasileira, a responsável pela coordenação do PEIBF é a coordenadora das séries iniciais; na escola uruguaia, a diretora é a responsável por todos os assuntos pedagógicos da escola. Foinos relatado que, nos anos anteriores, era o IPOL, Instituto de Investigação e Desenvolvimento em Política Linguística, que cuidava do assessoramento do PEIBF. Na escola brasileira, mencionou-se que a assessoria fazia reuniões com os professores da escola, porém poucas visitas foram recebidas, o que tornou as reuniões precárias. Na escola uruguaia, relatou-se que, em 2009, havia oficinas para capacitação dos professores. Além disso, o Departamento de Segunda Lengua ofereceu uma oficina sobre bilinguismo na escola, da qual participaram todos os professores das duas escolas, não somente os que trabalham com o projeto.

A partir de 2011, a assessoria do PEIBF nas escolas espelho deste estudo passou a um grupo de professores da Universidade Federal de

13. Essa Informação é de Thomaz (2010), entretanto, no site do MEC (http://portal. mec.gov.br/index.php? option $=$ com_content $\&$ view $=$ article $\&$ id $=12586 \&$ Item id=835), há registro de 14 escolas, entretanto, ao acessar a tabela com a lista das escolas (portal.mec.gov.br/arquivos/pdf/tabela_fronteira.pdf), são 13 as escolas. As informações, portanto, são desencontradas. Os acessos a esses links foram feitos em 18.04.2012.

14. Disponível em: <mre.gov.br/daí/b_urug_268_3976.htm>, acesso em 10 de jul. de 2011. 
Rio Grande/RS. Segundo informação recebida dos responsáveis, o MEC deveria lançar, em março de 2012, edital para que cada grupo assessor apresentasse projeto para custear as despesas decorrentes da implementação ${ }^{15}$.

Não há nada materiais didáticos disponíveis. Cada professor envolvido com o projeto elabora seus próprios materiais. Não há tema previsto pela escola ou assessoria ou MEC, são os alunos que escolhem os temas que desejam trabalhar durante as aulas de intercâmbio. Esses temas não são os mesmos das duas escolas, pois os interesses dos alunos variam. Os alunos das turmas do $1^{\circ}$ ano e $2^{\circ}$ ano, que já trabalhavam com o Projeto, escolhiam o tema para a escola uruguaia, e a maestra (professora) responsável pelo intercâmbio com a turma planejava a aula de intercâmbio a partir da temática escolhida. Alguns temas desenvolvidos pelos alunos foram, por exemplo, a origem das tintas, as baleias, os planetas e como surgiu a vida. Cada professor titular da turma envolvida cruza a fronteira e vai dar aula na escola espelho: a professora uruguaia dá sua aula em espanhol, e a professora brasileira, em português na turma uruguaia.

Um dado recorrente em ambas as entrevistas foi que, no segundo semestre de 2010, houve muitos feriados no Brasil, e o Projeto deixou de ter continuidade devido a esse fator. Como o "cruce" acontecia sempre (e somente) nas segundas-feiras e, havendo feriado nesse dia, o desenvolvimento do projeto ficava comprometido. Dar continuidade ao projeto é realmente um desafio. As rotinas de cada escola são importantes, mas um planejamento efetivo é necessário, também por parte de quem coordena e subsidia o PEIBF, como o próprio documento preliminar prevê.

[...] o currículo precisa basear-se em formas de organização das rotinas que permitam aos envolvidos de duas cidadanias e de várias culturas participarem nas tomadas das decisões e na execução de todas as fases do ensino, em todos os níveis em que isso se fizer necessário: o Planejamento Conjunto de Professores é um dos

15. Até o momento em que trabalhávamos neste artigo (abril de 2012), não vimos a publicação desse edital. 
pilares de tal procedimento [...] (grifo dos redatores) (MCyT; MEC, 2008).

Entendemos que pelo fato de o "cruce" acontecer num único dia da semana deveria prever a ocorrência de um número mínimo de intercâmbios e dias de trabalho com o Projeto, por semestre ou por mês, o que implica planejamento. Outro aspecto que tem se registrado como negativo na implementação do PEIBF até aqui é de sempre começar no segundo semestre. Como em ambos os países as aulas começam em março, parece que as escolas não têm muita autonomia no trabalho com o PEIBF, acabando por permanecer à espera de assessoria, e o Projeto fica parado. Em ambas as escolas, houve manifestações de que o projeto estava parado ou "dando para trás”, e esse sentimento provoca descrença nos objetivos e leva os envolvidos a pensar que faltam metas claras para se alcançar resultados positivos.

\section{Metodologia}

A pesquisa realizada é de natureza qualitativa, tendo como instrumentos de coleta de dados a entrevista semiestruturada e registros em diários de campo, gerados a partir de visitas às escolas, em julho e novembro de 2011. O campo de investigação é o ambiente de escolas espelho, uma brasileira e uma uruguaia. O grupo de sujeitos pesquisados neste estudo é composto das equipes diretivas e professores envolvidos na implementação do projeto.

A escolha da cidade deve-se ao fato de haver poucos trabalhos divulgados sobre a situação sociolinguística da região. A nosso ver, numa primeira observação, o quadro de bilinguismo aparenta ser diferente do restante da fronteira, parecendo-nos que não apresenta a mescla que se observa em Santana do Livramento/Rivera, por exemplo. Numa análise inicial das interações entre uruguaios e brasileiros nos espaços públicos, percebe-se que cada um interage em sua língua, não tentando falar a do outro. 


\subsection{As entrevistas}

As entrevistas semiestruturadas foram feitas a ambas as equipes diretivas e aos professores que já atuaram no projeto, a partir de doze perguntas, cujas respostas foram sendo anotadas e gravadas. As perguntas constavam dos seguintes temas: como a escola está se organizando para implantar o PEIBF, como a comunidade escolar recebe proposta, se há ou não materiais didáticos, se há capacitação para os professores, separada ou em conjunto com a escola espelho, se todos os alunos são da mesma nacionalidade, se foi feito um diagnóstico sociolinguístico para confirmar a necessidade do Projeto, se havia ou não verbas do governo federal para implantar esse trabalho, e, por último, como eram organizadas as aulas, se havia preocupação com a alfabetização e letramento na L2. As entrevistas duraram cerca de três horas com cada grupo na primeira vez e, na segunda, uma média de 23 minutos de entrevista, gravadas em áudio.

\subsection{O diário de campo e registros fotográficos}

Todos os demais comentários, percepções e impressões foram registrados em diário de campo. Do mesmo modo, foram feitos registros fotográficos, os quais dão uma ideia da estrutura física das escolas, não somente no que se refere às condições materiais, mas também à organização dos sistemas educativos em questão e à realidade visual das escolas. Também foram fotografados cartazes em lojas, os quais caracterizam o bilinguismo do local, que pode ser observado na avenida que separa as duas cidades.

\subsection{As escolas envolvidas}

A escola brasileira possui 340 alunos, distribuídos do $1^{\circ}$ ano ao $9^{\circ}$ ano, ou $8^{\text {a }}$ série, vem implantando também o currículo de 9 anos de Ensino Fundamental. São, em média, 25 alunos por turma, e 20\% deles são uruguaios. A escola conta, há 10 anos, com uma sala de inclusão, 
refeitório, consultório odontológico, brinquedoteca, biblioteca, auditório, laboratório de ciências, laboratório de informática, salas de aula e dependências administrativas.

A escola uruguaia é grande, possui várias salas de aula, atende 529 alunos, dos quais 212 almoçam na escola. Há, em média, 40 alunos em cada turma. No turno da tarde, parte do refeitório vira sala de aula para dar conta da demanda. Também há alunos brasileiros, ou que vivem na cidade brasileira. A equipe diretiva da escola informou que, na ficha de matrícula, há perguntas como situação sociofamiliar, língua familiar e nacionalidade. A escola não possui salas especializadas. Sobre a inclusão, foi destacado que os alunos devem ser incluídos na mesma turma que os demais e devem ser assistidos pelo professor com atividades diferenciadas. A escola também não tem um laboratório de informática, porém é contemplada com o Plan Ceibal do MEC uruguaio, que consta de um laptop por aluno. Os alunos recebem um notebook, com acesso à internet. Os aparelhos são de propriedade dos alunos.

As aulas devem ser baseadas na oralidade e não ter preocupação com a escrita. Reforçou-se que o PEIBF não trabalha a língua, mas visa à interculturalidade. Ao final de cada trabalho, no encerramento do projeto escolhido pelos alunos, é feita uma tarefa sobre o assunto, como uma apresentação à turma, por exemplo. O trabalho se pauta pela pedagogia de projetos, que é também uma prática de letramento, dado que, segundo Soares (2009), letramento é o "estado ou condição de quem não só sabe ler e escrever, mas exerce as práticas sociais de leitura e escrita que circulam na sociedade em que vive, conjugandoas com as práticas sociais de interação oral”. As escolas nos fizeram entender que, se há tarefas de produção escrita, não são cobradas com nota, o que está em conformidade com o já citado documento do MECyT e MEC (2008):

E uma escola e uma aula bilíngue; [...] recomenda a necessidade de que as crianças participem, no início, de uma etapa oral de contato com a segunda língua - enquanto participam de situações de leitura e escrita na sua língua materna. No âmbito das atividades com textos orais em segunda língua (conversações, jogos, canções, narrativas, rotinas 
escolares) previstas nos projetos que são desenvolvidos, as crianças aprendem formas de intercâmbio, o significado e uso de palavras e expressões e as regras de combinação desta língua. (MECyT; MEC, 2008)

Somado a isso, está o fato de o docente da aula de intercâmbio passar a ser a referência que os alunos terão da L2.

A escola brasileira oferece o ensino de língua espanhola desde o pré-escolar ao $5^{\circ}$ ano, em turno inverso ao das aulas, mas a alfabetização é feita na L1. Para tanto, a escola solicitou à Secretaria Municipal de Educação a ampliação da carga horária da professora de espanhol dos anos finais para que atendesse a essa demanda. Já o $6^{\circ}$ e o $7^{\circ}$ ano têm a disciplina de língua espanhola contemplada no seu currículo. Quanto ao $8^{\circ}$ e $9^{\circ}$ anos, as turmas têm a língua inglesa como adicional, porque a escola não oferece o Ensino Médio, e os alunos são transferidos à escola estadual, a qual só oferece a língua inglesa como LE. Para que os alunos estejam preparados para a etapa seguinte, a escola optou por essa distribuição de oferta de línguas adicionais. A escola espelho uruguaia, por sua vez, não oferece nenhuma língua adicional ou estrangeira, embora o Programa de Educación Inicial y Primaria preveja a inclusão de uma língua estrangeira.

\subsection{Entrevistados - Gestores e professores}

Os entrevistados são os gestores da escola brasileira, composta de um diretor, que é eleito por processo democrático junto à comunidade escolar, estando nesse cargo há um ano. Também compõem o grupo de entrevistados um vice-diretor, um coordenador pedagógico no turno da manhã que atende os anos finais do Ensino Fundamental o qual já foi responsável pelo PEIBF no primeiro ano de implantação (2009), e um coordenador pedagógico no turno da tarde, que atende aos anos iniciais e é o atual responsável pela coordenação do PEIBF na escola. Como o Programa até o momento se restringe aos anos iniciais, este coordenador, até a ocasião da entrevista, não tinha de fato trabalhado no PEIBF, porque em 2011 somente houve reuniões no 
MEC, em Brasília. Nessa escola, a direção não chamou os professores para participar da entrevista, por, no dia da visita, estarem atuando em outra escola.

$\mathrm{Na}$ escola uruguaia, os entrevistados são o diretor, o vice-diretor e dois professores dos anos iniciais, que estavam em sala de aula no turno em que marcamos as entrevistas. O diretor é responsável pela coordenação do PEIBF, e por todos os assuntos pedagógicos da escola, faz a gestão da escola há vinte anos e está próximo de sua aposentaria. O vice-diretor trabalha em turno integral na escola e é responsável pela administração e trabalhos burocráticos da escola, uma vez que não conta com secretário e com coordenadores pedagógicos.

\section{Resultados e discussão}

$\mathrm{Na}$ sequência, tecemos considerações a respeito da implementação do PEIBF, analisando representações e as atitudes de gestores e professores envolvidos diretamente na execução do projeto, em duas escolas espelho.

\subsection{Os gestores em relação aos sistemas educacionais: a percepção da diferença}

Em ambas as escolas, os gestores mostram uma atitude positiva em relação aos seus órgãos mantenedores. No caso da escola brasileira, a satisfação se deve ao fato de que a Secretaria de Educação atende a quase todas as suas solicitações, propiciando quase todos os recursos materiais e serviços de que a comunidade escolar necessita, talvez porque haja a vantagem de ser a única escola municipal da cidade. Esse atendimento às necessidades para o desenvolvimento do trabalho fortalece a identidade social dos envolvidos do lado brasileiro. Com a representação do "aqui é melhor", o NÓS parece se fortalecer em relação aos OUTROS, como, por exemplo, a manifestação da direção da escola em relação ao material didático: 
os professores daqui levavam para lá os recursos eram feitos na escola.

Isso também é manifestado por uma das professoras envolvidas, que afirmou levar daqui seu notebook e aparelho de som, porque a escola uruguaia não dispunha desse material.

$\mathrm{Na}$ escola uruguaia, por sua vez, fala-se com igual satisfação do sistema de ensino, mas em função da disciplina e da hierarquia. Nesse caso, a identidade é reforçada pela ideia da organização e da disciplina, características que também manifestam a diferença entre o AQUI (nós) e LÁ (os outros): "funciona tudo igual sob o mesmo regulamento, dá mais segurança trabalhar assim" (diário de campo, 12/07/2011). Segundo o diretor, "Alguns professores brasileiros não gostavam da presença do inspetor na aula e para nós isso é normal já nascemos com isso, aqui eu sei tudo o que acontece na sala de aula".

$\mathrm{O}$ conceito de educação inclusiva foi também levantado pela direção da escola uruguaia como representação das diferenças culturais dos sistemas de ensino brasileiro e uruguaio. Segundo esse gestor, fazemos adaptações com as crianças elas ficam na sala de aula normal, mas a avaliamos com indicadores diferentes, lá eles colocam em sala especial."

Apesar de serem parceiros de um projeto, parece que um grupo não conhece muito bem o sistema de ensino do vizinho: uma escola não sabia o número de dias letivos ou o horário de aulas da escola espelho. Do lado uruguaio, além de se demonstrar esse mesmo desconhecimento em relação ao sistema educativo brasileiro, foi demonstrada surpresa com a estrutura da equipe de gestão da escola brasileira (quantidade de recursos humanos envolvidos), sendo-lhes difícil entender exatamente a função de cada integrante.

Os gestores deixam marcas de sua identidade local em suas falas. Ao se manifestarem em relação ao sistema de ensino, de ambos os lados é marcada a diferença entre o aqui e o lá (cada um por suas razões), o que mostra que a construção identitária sempre se dá em relação aos outros e é socio-histórica. Do mesmo modo, nunca é pronta, acabada, porque, assim como as línguas mudam, nossas identidades também o fazem. O desconhecimento da realidade do 
outro, faz emergir as representações do tipo “aqui é melhor” (quando, na verdade, é apenas diferente). Até onde pudemos observar, não há um AQUI compartilhado, a identidade de fronteiriço não há.

\subsection{Representações e atitudes linguísticas}

Nas entrevistas com as equipes diretivas de ambas as escolas, foi possível identificar, nos seus discursos, a veiculação de diferentes representações e atitudes que circulam naquela comunidade, de modo especial aquelas relacionadas à língua que falam (e que os identifica como pertencentes àquelas comunidades) e em relação aos ganhos que teriam em participar do projeto.

\subsubsection{O prestígio do espanhol}

Em uma avaliação preliminar, parece-nos que o lado brasileiro fala com mais naturalidade do contato e da proximidade com o espanhol. Pareceu-nos, do contato que tivemos, que, em relação à língua do vizinho, há uma atitude mais positiva. A coordenação do PEIBF comentou:

a mãe ficou maravilhada com o filho aprendendo uma língua [...] Que lingua estás aprendendo? Aquela que tu fala.

Parece-nos que há a consolidação da representação "aprender espanhol é importante". Isso nos leva a crer que a política linguística brasileira de ensino do espanhol, em todas as escolas, ajuda a reforçar essa concepção. A fala da mãe, reproduzida pela professora, ratifica o prestígio dessa língua também na comunidade.

Do lado uruguaio, não nos pareceu haver a mesma preocupação em aprender o português. Ainda que exista a previsão, como mostramos acima, pouco contato há com essa língua, mesmo que de forma indireta. A direção da escola nos informou que as crianças agora veem mais televisão argentina, em função da televisão a cabo, e não têm mais tanto contato com o português como antes, quando 
a entrada da TV brasileira nos lares era hegemônica. Em relação à língua que falam, os entrevistados do lado uruguaio manifestam-se de forma muito positiva:

o espanhol daqui é diferente do resto do país, é mais puro, não vozeamos como no resto, não há mistura, nesta fronteira não há dialeto como nas outras, mas há bilinguismo"

(Diário de campo, 12/07/2011).

Ou seja, destacamos, aqui, identidades sociais fortes e atitudes positivas decorrentes das representações sociais relacionadas à variedade que falam ("nosso espanhol é melhor que nas outras cidades fronteiriças”).

\subsubsection{A interculturalidade - objetivo do PEIBF e dos envolvidos}

Participar de um projeto desacomoda. Enfrentar o desconhecido (sem material vindo pronto, com os alunos dizendo o que querem estudar) requer esforço de ambas as partes. É nesse desconhecimento da realidade alheia e do que vai vir da parte dos alunos que emergem as representações. A distância geográfica que separa um grupo de outro não é grande, mas foi o PEIBF que impôs o desafio de se trabalhar em conjunto: duas escolas diferentes, duas realidades diferentes, dois países diferentes. A representação de que "se somos tão próximos, deveríamos de nos conhecer" leva ao quase lamento de que a interculturalidade, que é um dos objetivos do projeto, não está acontecendo.

Do lado brasileiro, comentou-se que "o ganho até agora foi apenas linguístico”, o que, para quem observa de fora, pode não ser pouco. Parece que, muito mais que aprender a língua, é preciso conhecer o outro, pois a fronteira política existe e separa, não só dois países, mas duas culturas.

Como afirmou um dos sujeitos: tem que romper a fronteira (Diário de campo 12/07/2011). Rompendo a fronteira, aproximamonos do outro. De repente, até nos identificamos. Afinal, dividimos o mesmo espaço, o fronteiriço. 
Falta, ao que tudo indica, um planejamento de metas, similares ao que prevê o projeto geral do PEIBF - não haverá ensino DE língua do país vizinho, mas NA língua. Ao se dizer que inicialmente o projeto foi bom, mas depois "deu um pouco para trás" mostra-se a expectativa não satisfeita. Há, em nossa percepção, um sentimento de que há uma lacuna em relação às metas do PEIBF. Como os assuntos dos projetos têm sido de escolha dos alunos, e não especificamente tratam dos conteúdos curriculares, nem, na visão dos professores, da cultura da região, há uma sensação de que as metas não estão sendo atingidas.

Também na escola uruguaia se demonstrou interesse em trabalhar a interculturalidade, destacando que o PEIBF foi uma boa experiência, mas com resultados não apenas positivos porque as crianças, na sua avaliação, ficaram mais indisciplinadas (talvez pela forma como os professores brasileiros conduziam as aulas). A representação de que aula boa é aula disciplinada está presente aqui. A mesma tendência de um rigor maior parece transparecer na fala da direção: a princípio adoramos a ideia, apostamos no intercâmbio das duas fronteiras e na cultura, mas faz falta ter uma meta [...]. Quer dizer, tinha-se uma expectativa, um pré-conceito: vai haver troca cultural, vamos conhecer melhor nossos vizinhos, o que, entretanto, se frustrou.

Do mesmo modo que no lado brasileiro, há um sentimento de que faltam metas e definição para o que se entende por interculturalidade, pois, segundo a direção, "deveria ter temas mais culturais" que parece não estar presente, na percepção desses informantes, quando se trabalha com ciências naturais, com animais que não há na região, como a baleia, por exemplo, ou ainda quando se pesquisa como surgiram as tintas.

\subsubsection{A metodologia do PEIBF: "aluno não sabe escolher o tema"}

Historicamente coube ao professor definir os conteúdos a serem trabalhados com os alunos (ele, por sua vez, é regulado pela escola e pelos documentos oficiais). A proposta do PEIBF é que os alunos negociem a escolha do assunto a ser trabalhado. Isso causa 
um desconforto entre os envolvidos, uma vez que o professor, cujo papel sempre foi o de "autoridade", agora precisa ceder seu espaço na negociação. A ideia do PEIBF, com essa metodologia de trabalho, é possibilitar que se escolham temas a serem desenvolvidos localmente, por turma ou por escola, conforme se considere mais oportuno e conforme as diferentes realidades das escolas em questão (MCyT; MEC, 2008).

$\mathrm{Na}$ conversa com as direções, pode-se constatar certa insatisfação com a metodologia de escolha de temas para os projetos. Estamos aqui diante de um problema de papeis que são representados no âmbito da escola: o professor recebe uma lista de conteúdos, que precisam ser trabalhados. Essa lista está acima de quaisquer interesses. Isso fica claro na fala da direção do lado brasileiro, quando reivindica autonomia para escolher o tema para os alunos. Afinal, cabe ao professor o papel de dizer o que o aluno deve aprender, por isso um dos sujeitos acha que seria melhor o tema estar de acordo com os conteúdos programáticos por causa do tempo e para ter vínculo com a aprendizagem.

Talvez tenha faltado preparação dos professores que fariam os cruces, para que entrassem na negociação dos temas com os alunos. Talvez aí os resultados tivessem sido melhores (pelo menos do ponto de vista dos professores). As escolas espelho do nosso exemplo parecem concordar em relação a essa questão e não veem nessa escolha aleatória de assuntos alguma prática social que deveria fazer parte do ensino na L2. Até o presente momento, acompanharam o desenvolvimento da curiosidade intelectual dos alunos, mas faltaram temas como o exercício da cidadania e a participação ativa e crítica na sociedade.

Faltaria diálogo entre todos da comunidade escolar para sensibilização à importância do PEIBF? De que maneira duas culturas escolares diferentes podem contribuir e acrescentar algo uma à outra? Faltaria, talvez, num primeiro momento, uma compreensão mútua das escolas e dos proponentes do PEIBF, para depois se chegar ao planejamento e à sala de aula, aos objetivos e às metas do Projeto. E isso, no nosso entender, conduziria à interculturalidade desejada. 


\section{Considerações finais}

O PEIBF foi idealizado para propor um diálogo entre dois sistemas de ensino com estruturas e valores distintos. Um primeiro entrave está na diferença dos calendários escolares. No Uruguai, há uma média anual de 155 dias letivos. Para o ano de 2011, a meta foi de, no mínimo, 180 dias, em função de um projeto de lei que tramita no legislativo para aumentar a jornada letiva por ano. Em 2012, de acordo com tal projeto, espera-se o cumprimento de um mínimo de 190 dias e, a partir de 2013, um mínimo de 200 dias letivos de aula (manchete: Presidente quiere que parlamento defina cantidad de días de clase $\left.{ }^{16}\right)$. No Brasil, temos 200 dias letivos, mas com um calendário escolar próprio. Um exemplo dessa necessidade de compatibilizar os calendários pode ser exemplificada com nossa primeira visita, que aconteceu no dia 12 de julho quando encontraríamos as duas escolas em atividade, uma vez que no Uruguai houve férias escolares de 27/06/2011 a 08/07/2011, e, no Brasil, de 18/07/2011 a 29/07/2011.

Um projeto comum entre as escolas espelho é bem mais complexo do que se poderia pensar, dado que se trata de uma vizinhança muito próxima e, ao mesmo tempo, distante, o que passa por atitudes de insegurança quanto à integração escolar através desse tipo de projeto. Cada uma das escolas representa, de forma prática e ativa, os seus sistemas de ensino e tem muito a ensinar ao outro. Como podemos perceber, através do que foi registrado aqui, as escolas têm alguns aspectos em comum, e, a partir daí, o diálogo intercultural poderia ser viabilizado. É justamente nas diferenças que o trabalho poderia ser enriquecido, por meio da troca de ideias e experiências, o que reforçaria a interculturalidade, objetivo primeiro do PEIBF, e também manifestado pelas pessoas ouvidas.

Muito mais do que desenvolver aulas DE L2, ou NA L2, parecenos que os conteúdos deveriam estar vinculados à cultura da região e às ricas vivências que ambas podem intercambiar. Um exemplo está

16. Fonte: El País. <http://www.elpais.com.uy/110222/pnacio-548973/nacional/ presidente-quiere-que-parlamento-defina-cantidad-de-dias-de-clase $>$ de 22/02/2011, acesso em: 03/08/211. 
no fato de os alunos da escola brasileira serem acostumados a fazer campanhas sobre temas de cidadania e expor trabalhos à comunidade. $\mathrm{Na}$ escola uruguaia, com frequência, um familiar vai até a escola apresentar um trabalho à turma com seu filho. Também há orgulho pela pátria e pelos costumes locais, que podem ser compartilhados entre si. Então, partir do conhecimento de como o outro vê a região, a cultura, a língua, os seus costumes, o que estão fazendo para uma data comemorativa qualquer, para a chegada das férias, a volta delas, enfim, tudo o que envolve a rotina escolar, práticas sociais do aluno cidadão da fronteira, pode ser conteúdo de aula e, por extensão, de intercâmbio. Até mesmo projetos interdisciplinares abarcando conteúdos relativos às datas comemorativas poderiam ser aproveitados, o que ampliaria a visão do aluno em relação a si mesmo e ao outro. Trabalhar na L2 um conteúdo que aprendeu na L1 com outro professor, com outro ponto de vista, pode ser muito enriquecedor.

Igualmente interessantes são os pontos de vista e conceitos sobre educação de cada grupo de professores, como, por exemplo, o conceito de inclusão, mencionado anteriormente. Este ou qualquer outro debate seria importante e poderia acrescentar muito a um e outro grupo. Há ainda, por exemplo, a questão do uso de uniforme ou não. Na escola brasileira, como em muitas do país, não há obrigatoriedade de uniforme; na escola uruguaia, como em toda escola pública daquele país, é obrigatório o uso da "túnica y moño azul”, guarda-pó branco e laço azul, dentro de um conceito de igualdade entre todos (inclusive os professores e direção usam essa túnica). São questões culturais relevantes ao conhecimento entre vizinhos e cidadãos de fronteira, por meio das quais pode ser desenvolvida uma atitude de respeito à diferença.

No momento em que as escolas tiverem registrado em seus regimentos o trabalho com o $\mathrm{PEIBF}$, tendo o consenso da comunidade escolar, parece-nos desnecessário aguardar todos os anos o MEC brasileiro dar início aos trabalhos. Se as escolas já sabem como proceder e têm sua assessoria pedagógica para o PEIBF, seria um ganho maior às comunidades escolares envolvidas começar os projetos e as aulas de intercâmbio no início do ano, junto com toda a rotina escolar, e não desperdiçar mais de um semestre sem nada acontecer, o que prejudica 
a formação (inter)cultural dos alunos e o atendimento dos objetivos do PEIBF. O prejuízo é de todos. O PEIBF vem a ser uma das novas tarefas de política linguística do Brasil: manter em plena atividade um projeto dessa dimensão social, política e intercultural.

Por tudo o que foi visto e estudado a respeito do PEIBF, a educação linguística na L2, embora não apresentada em palavras, é o objetivo desse projeto multilateral. Segundo Bagno e Rangel (2005, p. 63), educação linguística se trata do

conjunto de fatores socioculturais que, durante toda a existência de um individuo, lhe possibilitam adquirir, desenvolver e ampliar o conhecimento de/sobre sua língua materna, de/sobre outras línguas, sobre a linguagem de um modo mais geral e sobre todos os demais sistemas semióticos. Desses saberes, evidentemente, também fazem parte as crenças, superstições, representações, mitos e preconceitos que circulam na sociedade em torno da língua/linguagem [...]o aprendizado de normas de comportamento linguístico que regem a vida dos diversos grupos sociais, cada vez mais amplos e variados, em que o individuo vai ser chamado a se inserir.

O PEIBF configura um projeto para a educação formal e tenciona dar conta de aspectos socioculturais e interculturais. Se vamos pensar no ensino da e na L2, a interculturalidade passa a ser o meio de chegar ao objetivo, que é a troca, o intercâmbio e o respeito à diferença, e não um fim em si mesma. As escolas-espelho de nosso estudo oferecem os mesmos níveis de ensino, cada uma dentro do seu sistema de ensino, do seu calendário escolar e de sua concepção de educação. Ainda que pareçam terem diferentes concepções de ensino de segunda língua (e a necessidade de educação linguística bilíngue), compartilham entre si um aspecto fundamental: sua percepção na necessidade de uma formação intercultural para seus alunos, que promova a integração da fronteira e o respeito à diversidade. E esse pode ser o ponto de partida para a implementação do PEIBF.

Recebido em: março de 2012

Aprovado em: abril de 2012 doroteafk@unisinow.br greicicanete@gmail.com 


\section{Referências bibliográficas}

ACORDO PARA CRIAÇÃO de Escolas e-ou Institutos Binacionais Fronteiriços. Disponível em: <mre.gov.br/daí/b_urug_268_3976.htm>, acesso em 10 de jul. de 2011.

APPEL, René, MUYSKEN, Pieter. Bilingüismo y contacto de lenguas. Barcelona: Ariel Lingüística, 1996.

ARGENTINA. Ley que reglamenta la obligatoriedad de la enseñanza del portugués en las escuelas secundarias, Ley $\mathbf{n}^{\mathbf{0}} \mathbf{2 6 . 4 6 8 / 2 0 0 8}$. Disponível em: $<$ http://www.bnm.me.gov.ar/giga1/normas/13516.pdf > Acesso em: 02 de março 2012.

BAGNO, Marcos e RANGEL, Egon de Oliveira. Tarefas da educação linguística no Brasil. Rev. Brasileira de Linguística Aplicada, v.5, n. 1, 2005, p. 63 a p. 81 .

BAKER, Colin. Fundamentos de Educación Bilingüe y Bilingüismo. Madrid: Ediciones Cátedra, 1993.

BARCELOS, A. M. F. Crenças sobre aprendizagem de línguas, Lingüística Aplicada e ensino de línguas. Linguagem \& Ensino, Vol. 7, No. 1, 2004, p. 123-156.

BESADA P., DELGADO, E.. Presidente quiere que parlamento defina cantidad de días de clase. In: El País. < http://www.elpais.com.uy/110222/ pnacio-548973/nacional/presidente-quiere-que-parlamento-definacantidad-de-dias-de-clase > acesso em 03 de ago de 2011.

BRASIL. PRESIDÊNCIA DA REPÚBLICA CASA CIVIL. Lei nº11.161 de cinco de agosto de 2005. Dispõe sobre o ensino de língua espanhola. Disponivel em: $<\quad$ http://www.planalto.gov.br/ccivil_03/_Ato20042006/2005/Lei/L11161.htm.> Acesso em 11 de fevereiro de 2012.

CALVET, Louis-Jean. Sociolingüística: uma introdução crítica. São Paulo: Parábola, 2002.

. As políticas linguísticas. São Paulo: Parábola, 2007.

GARCIA, Fernando Cacciatore de. Fronteira iluminada. História do povoamento, conquistas e limites do Rio Grande do Sul, a partir do Tratado de Tordesilhas (1420 -1920). Porto Alegre: Sulina, 2010. 
HALL, Stuart. Identidade Cultural na pós-modernidade.São Paulo: DP\&A, 2005

FISHMAN, J. Sociologia del lenguage. Madrid: Cátedra, 1995.

MACKEY, William. Las dimensiones de la política del language. In TERBORG, R. e GARCÍA, L. Los retos de la planificación Del lenguaje em el siglo XXI, México: UNAM, 2008, p.21-58.

MECyT \& MEC. Programa Escolas Bilíngues de Fronteira: modelo de ensino comum em escolas de zona de fronteira, a partir do desenvolvimento de um programa para a educação intercultural, com ênfase no ensino do português e do espanhol. Buenos Aires e Brasília: 2008. Disponível em: <http://portal. mec.gov.br/seb/arquivos/pdf/Escola fronteiras/doc_final.pdf $>$. Acesso em: 23 de jul. de 2011.

MINISTÉRIO DA EDUCAÇÃO. Tabela de escolas envolvidas no Projeto Escolas Interculturais Bilíngues de Fronteira. Disponível em: < http://portal.mec.gov.br/ arquivos/pdf/tabela_fronteira.pdf> Acesso em: 16 de abril de 2012.

MOSCOVICI, S. A representação social da psicanálise. Rio de Janeiro: Zahar Editora, 1978.

. Representações sociais: investigações em psicologia social.

Petropólis: Vozes, 2003.

MYERS-SCOTTON, C. Multiple Voices: An Introduction to Bilingualism. Blackwell, 2006.

SCHLATTER, Margarete, GARCEZ, Pedro. Referencial curricular: Língua Espanhola e Língua Inglesa. In: SECREATARIA DE EDUCAÇÃO DO ESTADO DO RIO GRANDE DO SUL. Lições do Rio Grande: linguagens Códigos e suas Tecnologias, Língua Portuguesa e Literatura, Língua Estrangeira Moderna. v.1, 2009.

SCHNEIDER, M. N. Atitudes e concepções lingüísticas e sua relação com as práticas sociais de professores em comunidades bilíngües alemãoportuguês do Rio Grande do Sul. Tese de Doutorado. Instituto de Letras, Universidade Federal do Rio Grande do Sul, mimeo, 2007.

SOARES, Magda. Letramento: um tema em três gêneros. 3. ed., Belo Horizonte: Autêntica, 2009.

THOMAZ, Karina Mendes. A política linguística do projeto escolas interculturais bilíngues de fronteira do MERCOSUL: ensino de segunda 
língua para as áreas fronteiriças. Revista línguas e letras Vol. $11-\mathrm{N}^{\circ} 21$ - $2^{\circ}$ Semestre de 2010. Disponível em: <e-revista.unioeste.br/index.php/ linguaseletras/ article/download/3545/3462> acesso em 10 de jul. de 2011. URUGUAI. Administración Nacional de Educación Pública. Disponível em: <http://www.anep.edu.uy/anepportal/servlet/main004?229> Acesso em: 16 de abril de 2012.

URUGUAI. Instituto de Profesores Artigas. Disponível em: < $\underline{\text { http://www. }}$ dfpd.edu.uy/ipa/index.html 16/04/211. 